JINOTEP Vol 6 (2) (2020): 69-80

DOI: 10.17977/um031v6i22020p069

JINOTEP (Jurnal Inovasi Teknologi Pembelajaran)

Kajian dan Riset Dalam Teknologi Pembelajaran

http://journal2.um.ac.id/index.php/jinotep/index

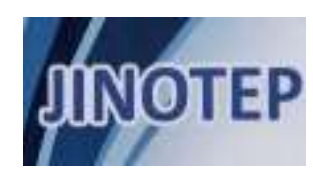

\title{
PENGEMBANGAN MULTIMEDIA TUTORIAL SEBAGAI SUPLEMEN PADA MATA PELAJARAN KIMIA MATERI ASAM DAN BASA KELAS XI
}

\author{
Dyas Nurika Prastiwi, Punaji Setyosari, Arafah Husna \\ Jurusan Teknologi Pendidikan, FIP, Universitas Negeri Malang \\ Jalan Semarang 5 Malang 65145, Telp. (0341) - 574700
}

\begin{tabular}{l}
\hline Article History \\
\hline Received: $01-05-2019$ \\
Accepted:20-05-2019 \\
Published:30-04-2020
\end{tabular}

\section{Keywords}

multimedia tutorial, suplemen, kimia, asam dan basa

\begin{abstract}
Abstrak
Guru dan peserta didik membutuhkan media pembelajaran tambahan (suplemen) yang menarik perhatian, mampu meningkatkan antusiasme peserta didik, mengoptimalkan pembelajaran, serta dapat membantu mencapai tujuan pembelajaran. Tujuan penelitian dan pengembangan ini adalah menghasilkan produk berupa multimedia tutorial yang layak sebagai suplemen pada mata pelajaran Kimia materi Asam dan Basa kelas XI. Pengembang memilih model penelitian dan pengembangan William W.Lee dan Diana L.Owens yang terdiri dari tahap analisis kebutuhan, desain multimedia, pengembangan multimedia, implementasi multimedia dan evaluasi multimedia. Berdasarkan hasil validasi multimedia tutorial sebagai suplemen oleh ahli media didapatkan persentase sebesar $95,78 \%$, ahli materi $83,52 \%$, guru $85,88 \%$, serta uji coba kelompok kecil $84,47 \%$ dan uji coba kelompok besar $85,58 \%$. Dapat disimpulkan bahwa multimedia tutorial sebagai suplemen pada mata pelajaran Kimia materi Asam dan Basa kelas XI SMA sangat layak digunakan.
\end{abstract}

\begin{abstract}
Teacher and students need learning media as a supplement that can attract attention, rising enthusiasm of students, optimize learning, and help them to achieve learning goals. The purpose of this research and development is to produce a product of multimedia tutorial as a proper and valid supplement used in Chemistry subject Acid and Bases material for class XI. The developer chooses the research and development model William W. Lee and Diana L. Owens which consists of the needs analysis, multimedia design, multimedia development, multimedia implementation and multimedia evaluation stages. Based on the results of the multimedia tutorial validation as a supplement by media experts, there was a percentage of $95.78 \%, 83.52 \%$ from material experts, $85.88 \%$ from teachers, also $84.47 \%$ and $85.58 \%$ from trial test of students. It can be concluded that multimedia tutorials as a supplement in the Chemistry subject, Acid class Base material of XI SMA are very suitable to use.
\end{abstract}

Corresponding author :

Adress: Jl. Gajah Mada, Desa Jalen, Kecamatan Balong, Kabupaten

Ponorogo, Jawa Timur, Indonesia,

Instansi: Universitas Negeri Malang,

E-mail: nurikaprastiwi@gmail.com,

\footnotetext{
E-mail: nurikaprastiwi@gmail.com,
}

2020 Universitas Negeri Malang p-ISSN 2406-8780 e-ISSN 2654-7953 
70 JINOTEP (Jurnal Inovasi dan Teknologi Pembelajaran) Kajian dan Riset dalam Teknologi Pembelajaran Vol.6, No. 2, April 2020, Hal 69-80

\section{PENDAHULUAN}

Belajar merupakan suatu proses perubahan di dalam kepribadian manusia yang ditunjukkan dalam bentuk peningkatan kuantitas serta tingkah laku seperti peningkatan kecakapan, pengetahuan, sikap, kebiasaan, pemahaman, keterampilan, daya fikir, dan kemampuan lainnya (Hakim, 2005; Mezirow, 1997; Schunk, 2012). Belajar tidak terjadi tanpa adanya minat atau perhatian. Keller menyatakan bahwa minat dan perhatian tidak sekedar dibangkitkan, namun juga harus dipelihara selama kegiatan pembelajaran berlangsung.

Guru dituntut memberikan inovasi baru agar peserta didik mampu mendapatkan pengalaman baru dalam kegiatan pembelajaran. Inovasi diperlukan agar proses pembelajaran tidak monoton. Inovasi dalam pembelajaran dapat berupa pengembangan bahan ajar, media, maupun metode pembelajaran (Tuerah, 2017). Mayoritas guru menggunakan papan tulis dan buku sebagai media pembelajaran. Selain hal tersebut, metode pembelajaran yang digunakan oleh para guru masih konvensional, yaitu metode ceramah.

Hambatan dalam pelaksanaan proses pembelajaran, yaitu kurangnya pemanfaatan media pembelajaran pendukung. Pembelajaran monoton yang hanya menggunakan komunikasi secara verbal juga menyebabkan peserta didik mudah bosan. Dalam proses pembelajaran terdapat kegiatan interaksi antara guru dengan peserta didik meliputi kegiatan kognitif, afektif, dan psikomotorik. Kualitas pembelajaran pada umumnya berupa hasil yang berkualitas berkenaan dengan pengalaman belajar atau kurikulum dan pelajaran (Setyosari, 2017). Media pembelajaran mendukung pelaksanaan proses pembelajaran, serta tercapainya tujuan pembelajaran.

Pada mata pelajaran Kimia kelas XI SMA, peserta didik mempelajari materi tentang Asam dan Basa. Beberapa sub materi di dalamnya membutuhkan ilustrasi dan visualisasi agar lebih mudah dipahami, misalnya mengenai teori asam dan basa, uji larutan elektrolit dan non elektrolit, serta eksperimen asam dan basa. Apabila hanya menggunakan media cetak (buku), peserta didik mengalami kesulitan, pembelajaranpun kurang maksimal, serta tujuan pembelajaran sulit dicapai. Guru maupun peserta didik membutuhkan media pembelajaran yang dapat mengatasi permasalahan-permasalahan yang ada.

Oleh karena itu, diperlukan adanya media pembelajaran tambahan (suplemen) untuk membantu proses pembelajaran. Hal tersebut didukung juga oleh Peraturan Menteri Pendidikan Nasional No. 87 tahun 2013 tentang Program Pendidikan Profesi Guru Prajabatan Pasal 1, dimana guru dituntut untuk mengembangkan perangkat pembelajaran yang komprehensif (Kemendikbud, 2013). Salah satunya mencakup pengadaan media pembelajaran yang interaktif dan menarik, misalnya multimedia tutorial. Multimedia tutorial mencakup materi tulisan, gambar, suara, serta video.

Multimedia merupakan penggunaan komputer untuk menyajikan dan menggabungkan teks, suara, gambar, animasi dan video dengan alat bantu (tool) dan koneksi (link) sehingga pengguna dapat melakukan navigasi, berinteraksi, berkarya dan berkomunikasi (Hartati, 2017; Hofstetter, 2001; Mohsen, 2016; A. R. Wijaya, Kuswandi, \& ..., 2019). Menurut (R. E. Mayer \& Moreno, 1998; R. Mayer \& Mayer, 2005; Moreno \& Mayer, 2000) penyajian teks berupa tulisan atau lisan dan gambar berupa ilustrasi, foto, animasi, atau video dapat disebut sebagai multimedia. Multimedia tutorial merupakan salah satu media pembelajaran berbasis komputer yang dapat menarik perhatian, antusiasme peserta didik, mengoptimalkan pembelajaran, serta dapat membantu mencapai tujuan pembelajaran.

Berdasarkan hasil observasi dan wawancara terhadap guru dan beberapa 
peserta didik, teknologi komputer belum dimanfaatkan secara optimal dalam kegiatan pembelajaran Kimia materi Asam dan Basa di SMA Negeri 2 Ponorogo, sehingga menyebabkan turunnya motivasi dan minat belajar peserta didik. SMA Negeri 2 Ponorogo memiliki fasilitas laboratorium komputer, terdapat proyektor di setiap kelas, dan para peserta didiknya juga telah menguasai teknologi. Meskipun SMA Negeri 2 Ponorogo menyediakan fasilitas laboratorium kimia, namun alat dan bahan untuk melakukan suatu percobaan masih kurang. Pada sebagian sub bab materi, yaitu eksperimen asam basa dan uji larutan elektrolit dan non elektrolit peserta didik perlu melakukan percobaan atau setidaknya melihat video tentang materi tersebut agar pemahaman peserta didik lebih konkret. Sedangkan buku saja tidak cukup untuk mencapai tujuan pembelajaran.

Multimedia tutorial sebagai suplemen akan memberikan suasana berbeda yang dapat mengubah pemikiran serta menambah pengalaman peserta didik. Pemanfaatan multimedia tutorial sebagai suplemen pada proses pembelajaran dapat menggeser pembelajaran yang membosankan menjadi pembelajaran yang menyenangkan dan menarik. Peserta didik lebih antusias untuk mempelajari materi Asam dan Basa Kimia. Pemanfaatan multimedia tutorial sebagai suplemen pada mata pelajaran Kimia menjadikan peserta didik aktif dalam belajar dan guru tidak menjadi satu-satunya sumber belajar. Multimedia tutorial juga dapat memberikan pengetahuan yang lebih konkret. Ketertarikan peserta didik pada multimedia tutorial juga akan meningkatkan motivasi belajar peserta didik. Multimedia tutorial memberikan peluang belajar mandiri bagi peserta didik, sehingga belajar bisa dilakukan kapan saja dan dimana saja dengan bantuan laptop/pc yang dimiliki.

Keunggulan Autoplay adalah siapapun dapat membuat multimedia interaktif, meskipun bukan seorang programmer, karena dengan menggunakan program Autoplay pengguna dapat membuatnya dengan cara yang lebih sederhana. Proyek yang dibuat terlihat profesional dengan memanfaatkan program ini (Rosyida \& Adi, 2018). Pembelajaran menggunakan multimedia interaktif model tutorial menjadikan peserta didik bersemangat mengikuti proses pembelajaran dengan baik. Pembelajaran lebih menarik sehingga peserta didik termotivasi untuk belajar lebih lanjut. Selain itu, peserta didik dapat mengulang kembali materi yang telah dipelajari (Khoerunisa, Maknun, \& Mulyani, 2014; Sunarya, Rahardja, Aini, \& Khoirunisa, n.d.)

Tujuan penelitian dan pengembangan ini adalah menghasilkan produk berupa multimedia tutorial yang layak sebagai suplemen pada mata pelajaran Kimia materi Asam dan Basa untuk kelas XI SMA Negeri 2 Ponorogo.

\section{METODE}

Model pengembangan yang digunakan yaitu model penelitian dan pengembangan (Research \& Development) yang dikemukakan oleh William W.Lee dan Diana L.Owens. Alasan pemilihan karena model ini dikhususkan untuk pengembangan multimedia (Lee \& Owens, 2004).

Terdapat lima tahapan pengembangan, yaitu: 1) Multimedia Needs Assesment and Analysis; 2) Multimedia Instructional Design; 3) Multimedia Development; 4) Multimedia Implementation; 5) Multimedia Evaluation.

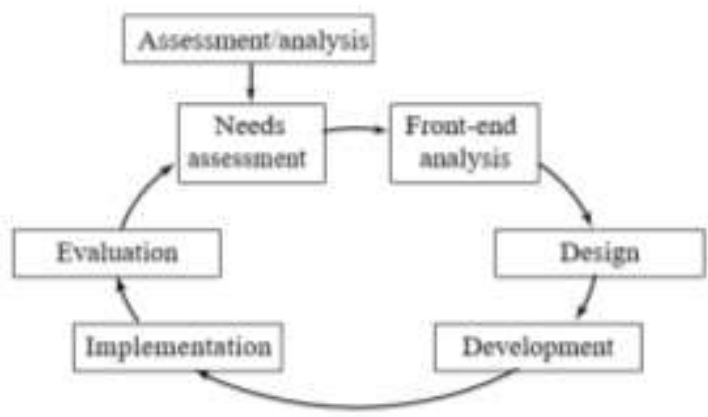

Gambar 1 Model Pengembangan William W.Lee dan Diana L.Owens (2004) 
72 JINOTEP (Jurnal Inovasi dan Teknologi Pembelajaran) Kajian dan Riset dalam Teknologi Pembelajaran Vol.6, No. 2, April 2020, Hal 69-80

Tahap pertama yaitu tahap penilaian dan analisis (assessment/analysis), terdiri dari dua bagian yaitu penilaian kebutuhan (need assessment) serta analisis awal akhir (frontend analysis) (Lee \& Owens, 2004).

\section{Need Assessment (Analisis Kebutuhan)}

Proses analisis kebutuhan melalui metode wawancara langsung dan observasi. Dalam tahap ini, peneliti melakukan observasi di SMA Negeri 2 Ponorogo. Peneliti melakukan wawancara awal dengan guru dan peserta didik SMA Negeri 2 Ponorogo, khususnya guru Kimia kelas XI dan peserta didik kelas XI yang memperoleh mata pelajaran Kimia. Hasil observasi awal yang dilakukan pengembang adalah peserta didik Kelas XI MIPA SMA Negeri 2 Ponorogo memperoleh mata pelajaran Kimia, yang di dalamnya terdapat materi Asam dan Basa. Dalam pembelajaran, biasanya guru menggunakan modul. Peserta didik mengalami kesulitan untuk memahami beberapa sub materi, dikarenakan kurangnya ilustrasi dan visualisasi dalam modul. Motivasi belajar peserta didikpun menurun. Meskipun SMA Negeri 2 Ponorogo menyediakan fasilitas laboratorium kimia, namun alat dan bahan untuk melakukan suatu percobaan masih kurang. Pada sebagian sub bab materi, yaitu eksperimen asam basa dan uji larutan elektrolit dan non elektrolit peserta didik perlu melakukan percobaan atau setidaknya melihat video tentang materi tersebut agar pemahaman peserta didik lebih konkret. Sedangkan buku saja tidak cukup untuk mencapai tujuan pembelajaran. Dapat disimpulkan bahwa guru dan peserta didik kelas XI SMA Negeri 2 Ponorogo membutuhkan multimedia tutorial sebagai suplemen pada mata pelajaran Kimia materi Asam dan Basa.

\section{Front-end Analysis (Analisis Awal- Akhir)}

Tahap front-end analysis bertujuan untuk mendapatkan informasi yang lebih lengkap tentang hal yang akan dikembangkan. Tahap ini terdiri dari analisis peserta didik (audience analysis), analisis teknologi (technology analysis), analisis situasi (situation analysis), analisis tugas (task analysis), analisis kejadian penting (critical analysis), analisis tujuan (objective analysis), analisis masalah (issue analysis), analisis media (media analysis), analisis data yang sudah ada (extant-data analysis) dan analisis biaya (cost analysis)(Lee \& Owens, 2004).

\section{(1) Analisis Peserta Didik}

Analisis peserta didik merupakan langkah untuk mengidentifikasi karakteristik peserta didik. Pengembangan media disesuaikan dengan hasil analisis ini. Analisis peserta didik meliputi jumlah peserta didik yang berada pada kelas XI MIPA SMA Negeri 2 Ponorogo, karakteristik peserta didik dalam proses pembelajaran, respon peserta didik terhadap pembelajaran oleh guru, dan sebagainya. Subjek penelitian ini adalah peserta didik kelas XI MIPA 5 SMA Negeri 2 Ponorogo, mayoritas peserta didik memiliki laptop/pc dan dapat mengoperasikannya dengan baik. Sebelumnya, peserta didik telah mempelajari materi Larutan Elektrolit, Ikatan Kimia, serta Konsep Mol.

\section{(2) Analisis Teknologi}

Analisis ini mengidentifikasi kemampuan teknologi yang ada di SMA Negeri 2 Ponorogo. Hasil dari analisis teknologi menjadi acuan dalam perancangan media. Analisis teknologi juga bertujuan untuk menentukan teknologi yang dibutuhkan untuk pengembangan dan pengoperasian multimedia tutorial sebagai suplemen. Dari hasil analisis sementara yang dilakukan oleh pengembang, masing-masing peserta didik memiliki laptop/pc yang memadai serta dapat mengoperasikannya dengan baik. Selain itu, SMA Negeri 2 Ponorogo juga memiliki sarana lab komputer dan di setiap ruang kelas juga telah tersedia proyektor sehingga penelitian dan pengembangan multimedia tutorial sebagai suplemen dapat dilaksanakan di SMA Negeri 2 Ponorogo.

(3) Analisis Situasi

Analisis ini mencakup analisis situasi lingkungan belajar peserta didik. Lokasi 
sekolah, kondisi, serta hambatan atau masalah pada lingkungan belajar termasuk dalam analisis ini. Hal-hal tersebut digunakan bahan pertimbangan dalam perancangan multimedia tutorial sebagai suplemen pada mata pelajaran Kimia materi Asam dan Basa. Lingkungan dalam penelitian dan pengembangan ini adalah SMA Negeri 2 Ponorogo dengan jumlah laptop/pc yang memadai sebagai perangkat untuk menjalankan multimedia tutorial. Media pembelajaran yang dikembangkan merupakan suplemen pembelajaran, sehingga pemanfaatannya dapat dilakukan di dalam jam pembelajaran, maupun sebagai media pembelajaran mandiri untuk peserta didik di luar jam pelajaran.

\section{(4) Analisis Tugas}

Analisis tugas adalah prosedur untuk tugas-tugas yang perlu dikuasai oleh peserta didik terhadap materi pembelajaran, hal-hal yang harus dilakukan dan yang harus diketahui. Analisis ini menentukan persyaratan fisik dan mental untuk menyelesaikan suatu pekerjaan. Materi pada penelitian dan pengembangan ini diambil dari pembelajaran yang dianggap sulit dipahami oleh peserta didik. Pada tahap ini pengembang mengkaji indikator dan tujuan pembelajaran yang telah ditentukan dalam proses pembelajaran. Hasil dari analisis ini digunakan sebagai penentu materi pembelajaran yang akan digunakan. Dalam hal ini, pengembang memilih materi Asam dan Basa pada mata pelajaran Kimia Kelas XI SMA Negeri 2 Ponorogo.

\section{(5) Analisis Kejadian Penting}

Analisis ini perlu dilakukan untuk menentukan yang harus dan yang tidak harus diajarkan, menunjukkan tugas yang membutuhkan pelatihan atau informasi bagi pengguna. Hal tersebut dilakukan untuk menetapkan kinerja efektif yang akan dilaksanakan. Analisis kejadian penting juga dapat memberikan solusi terhadap masalah yang dihadapi, serta mengetahui tujuan yang ingin dicapai. Tugas-tugas yang harus dilakukan peserta didik antara lain adalah membaca pengantar dan petunjuk penggunaan multimedia tutorial sebagai suplemen serta menyiapkan laptop/pc yang spesifikasinya memadai.

(6) Analisis Tujuan

Menentukan tujuan atau sasaran pengembangan media pembelajaran. Analisis tujuan menentukan isi (materi pengetahuan), cara efektif mengukur keberhasilan, dan memilih media pembelajaran yang digunakan. Perumusan tujuan disesuaikan dengan kompetensi yang telah ditentukan. Terdapat lima domain belajar yang perlu diperhatikan dalam membuat tujuan, yaitu kognitif, afektif, gerak, psikomotor, dan metakognitif. Tujuan penelitian ini mengarah ke kognitif peserta didik kelas XI MIPA SMA Negeri 2 Ponorogo pada mata pelajaran Kimia materi Asam dan Basa.

\section{(7) Analisis Masalah}

Analisis masalah mengidentifikasi pokok permasalahan untuk menentukan media pembelajaran yang sesuai dengan guru dan peserta didik. Kegiatan ini diperlukan agar lebih fokus terhadap produk yang dikembangkan. Identifikasi pokok persoalan ini lebih mengacu pada tingkat pemahaman dan gaya belajar peserta didik. Hasil analisis ini digunakan sebagai acuan penentuan materi pembelajaran dan media pembelajaran yang sesuai dengan permasalahan dan kebutuhan.

(8) Analisis Media

Strategi penyampaian media yang sesuai berdasarkan hasil observasi dan wawancara. Analisis media dilakukan untuk menentukan bentuk serta isi media. Terdapat berbagai jenis media pembelajaran yang dapat digunakan, media disesuaikan dengan kebutuhan dan kondisi lapangan. Media pembelajaran disesuaikan dengan hasil analisis yang telah dilakukan sebelumnya. Dalam penelitian ini, peneliti mengembangkan multimedia tutorial sebagai suplemen pada mata pelajaran Kimia materi Asam dan Basa. Multimedia tutorial yang dikembangkan berisi Kompetensi Dasar yang harus dicapai, materi, serta beberapa soal 
74 JINOTEP (Jurnal Inovasi dan Teknologi Pembelajaran) Kajian dan Riset dalam Teknologi Pembelajaran Vol.6, No. 2, April 2020, Hal 69-80

evaluasi mengenai Asam dan Basa Kimia kelas XI.

(9) Analisis Data yang Sudah Ada

Analisis berikutnya adalah Extant Data Analysis (analisis data yang sudah ada). Analisis data dilakukan untuk memecahkan masalah yang ada. Terdapat beberapa kegiatan yang harus dilakukan yaitu, Mengidentifikasi sumber informasi; Mengumpulkan informasi dan bahan-bahan pembelajaran; Mengevaluasi informasi berdasarkan tujuan dan kebutuhan; Memutuskan akan membeli atau membuat; Mengevaluasi yang telah diputuskan; Mendokumentasikan hasilnya. Analisis data dalam penelitian dan pengembangan ini menggunakan instrumen/angket checklist (untuk ahli media, ahli materi, guru, serta peserta didik).

(10) Analisis Biaya

Analisis biaya merupakan analisis akhir penelitian. Analisis ini diperlukan untuk mengukur biaya yang diperlukan dalam pengembangan produk. Tahap analisis biaya mencakup kegiatan penentuan biaya, penggunaan biaya, dan pencatatan hasil akhir biaya. Banyaknya biaya yang diperlukan dalam pembuatan produk dijelaskan secara rinci.

\section{Desain}

Tahap kedua adalah tahap desain atau perancangan media. Tahap desain mencakup seluruh kegiatan pengembangan multimedia tutorial. Pengembang menyusun jadwal (schedule), menentukan spesifikasi media (media spesification), struktur konten (content structure), kemudian kontrol konfigurasi (configuration control).

\section{Pengembangan}

Tahap ketiga adalah tahap pengembangan produk, yaitu menerjemahkan spesifikasi produk ke dalam wujud fisik. Tahap pengembangan meliputi pembuatan kerangka berupa storyboard, pengembangan konten, serta review dan revisi produk. Storyboard berfungsi sebagai pedoman bagi pengembang dalam input materi, mengembangkan desain interface yang akan digunakan dalam produk multimedia tutorial. Mengembangkan penyajian konten yang disajikan dalam multimedia tutorial, melakukan review atau perbaikan dan revisi yang diperlukan sehingga produk dinilai layak untuk diimplementasikan dalam proses pembelajaran.

\section{Implementasi}

Tahap keempat adalah implementasi. Pada tahap implementasi, dilakukan validasi oleh ahli media, ahli materi, serta guru mata pelajaran. Setelah produk dinyatakan layak, kemudian diujicobakan kepada peserta didik.

\section{Evaluasi}

Tahap kelima adalah tahap evaluasi, pengembang melakukan evaluasi terhadap produk. Evaluasi yang dilakukan pada penelitian pengembangan ini adalah evaluasi yang berorientasi pada kevalidan produk yang dikembangkan melalui validasi oleh ahli media, ahli materi, guru, serta hasil uji coba produk. Tahap evaluasi ini berkaitan dengan tahap implementasi. Tahap evaluasi dilakukan setelah seluruh serangkaian kegiatan di tahap keempat (validasi ahli dan uji coba produk) dilakukan.

Tahap selanjutnya adalah uji coba produk. Subjek uji coba penelitian dan pengembangan multimedia tutorial sebagai suplemen pada mata pelajaran Kimia materi Asam dan Basa ini adalah peserta didik kelas XI MIPA 5 SMA Negeri 2 Ponorogo yang berjumlah 25 .

Pengumpulan data uji coba produk menggunakan angket penilaian. Angket penilaian digunakan untuk mengetahui pendapat responden terhadap multimedia tutorial sebagai suplemen pada mata pelajaran Kimia materi Asam dan Basa Kelas XI SMA. Jenis angket yang digunakan pada uji coba produk adalah angket tertutup. Pada angket tertutup, masing-masing pernyataan memiliki alternatif jawaban yang dapat dipilih oleh responden. Instrumen penelitian dan pengembangan ini berupa angket daftar cek (checklist) dengan skala likert. Data yang 
dikumpulkan berupa data kualitatif dan kuantitatif meliputi kemenarikan multimedia pembelajaran bagi peserta didik, relevansi multimedia pembelajaran yang dipelajari, kebermanfaatan multimedia pembelajaran yang dipelajari, kesesuaian multimedia pembelajaran yang dipelajari, serta kemudahan mengakses multimedia pembelajaran, menggunakan observasi, wawancara, kuesioner, dan dokumentasi.

Data diperoleh dari angket (kuesioner) yang diisi oleh ahli materi, ahli media, guru, dan peserta didik. Jenis data dalam penelitian dan pengembangan ini yaitu data kuantitatif yang didapat dari pengisian angket checklist serta data kualitatif yang diperoleh dari saran dan komentar subjek penelitian. Teknik analisis yang digunakan menggunakan kriteria penilaian dari (Arikunto, 2000, 2006) dengan menggunakan rumus skor tiap butir dan skor rata-rata.

Data kuantitatif yang diperoleh kemudian dianalisis dengan menggunakan teknik deskriptif persentase. Deskriptif persentase adalah mengubah data kuantitatif menjadi bentuk persentase untuk diinterpretasikan menjadi data kualitatif. Untuk menghitung persentase menggunakan rumus sebagai berikut:

$$
\mathrm{P}=\frac{x}{x_{i}} \times 100 \%
$$

Keterangan:

$$
\begin{array}{ll}
\mathrm{P} & =\text { Persentase } \\
x & =\text { jumlah skor penilaian dalam satu } \\
& \text { butir } \\
x_{i} & =\text { jumlah skor ideal dalam satu butir } \\
100 \% & =\text { bilangan konstan }
\end{array}
$$

Rumus skor rata-rata dari seluruh butir, yaitu

$$
\mathrm{P}=\frac{\Sigma x}{\Sigma x_{1}} \times 100 \%
$$

Keterangan:

$$
\begin{array}{ll}
\mathrm{P} & =\text { Persentase } \\
\Sigma \mathrm{X} & =\text { Jumlah skor yang didapat } \\
\Sigma \mathrm{X}_{1} & =\text { Jumlah skor maksimum } \\
100 \% & =\text { Konstanta }
\end{array}
$$

Tahap selanjutnya adalah menentukan persentase hasil penelitian pengembangan, kemudian dilakukan pemaknaan terhadap hasil. Semakin tinggi skor hasil analisis data, maka semakin baik tingkat kelayakan. Kriteria tingkat kelayakan analisis persentase produk hasil pengembangan disajikan dalam tabel berikut.

Tabel 1. Kriteria Kelayakan Produk menurut (Arikunto, 2009)

\begin{tabular}{cc}
\hline $\begin{array}{c}\text { Kriteria Kelayakan } \\
\text { (Persentase) }\end{array}$ & Kriteria Validasi \\
\hline $81 \%-100 \%$ & Sangat layak \\
\hline $61 \%-80 \%$ & Layak \\
\hline $41 \%-60 \%$ & Cukup layak \\
\hline $21 \%-40 \%$ & Tidak layak \\
\hline $0 \%-20 \%$ & Sangat tidak layak
\end{tabular}

Berdasarkan kriteria kelayakan, maka dapat ditentukan apakah item tersebut perlu direvisi atau tidak. Saran dari validator, guru, dan serta peserta didik turut menjadi pertimbangan pada tahap revisi produk.

Data kualitatif diperoleh dari angket yang diisi oleh ahli materi, ahli media, guru, serta peserta didik, berupa komentar dan saran. Hasil analisis data kualitatif dideskripsikan secara singkat. Meskipun item dinyatakan layak, tetapi komentar dan saran yang diberikan oleh validator serta pengguna harus dijadikan pertimbangan untuk memperbaiki produk. Ahli media dalam penelitian dan pengembangan ini adalah Dosen Teknologi Pendidikan, sedangkan ahli materinya adalah Dosen Pendidikan Kimia Universitas Negeri Malang.

\section{HASIL}

Produk yang dihasilkan pada penelitian dan pengembangan ini berupa multimedia tutorial sebagai suplemen pada mata pelajaran Kimia materi Asam dan Basa kelas XI SMA. Multimedia tutorial sebagai suplemen ini mencakup audio visual dalam bentuk teks, gambar, animasi, audio, dan video, sehingga dapat memotivasi dan menarik perhatian peserta didik, serta dapat mendukung tercapainya tujuan pembelajaran. 
76 JINOTEP (Jurnal Inovasi dan Teknologi Pembelajaran) Kajian dan Riset dalam Teknologi Pembelajaran Vol.6, No. 2, April 2020, Hal 69-80

Berdasarkan hasil validasi multimedia tutorial terhadap ahli media, ahli materi, guru, serta ujicoba terhadap peserta didik, didapatkan data sebagai berikut:

Tabel 2. Hasil Validasi dan Ujicoba

\begin{tabular}{cccc}
\hline No. & Responden & Hasil & Kriteria \\
\hline 1. & Ahli Media & $95,78 \%$ & Sangat layak \\
\hline 2. & Ahli Materi & $83,52 \%$ & Sangat layak \\
\hline 3. & Guru & $85,88 \%$ & Sangat layak \\
\hline \multicolumn{3}{c}{ Uji Coba } \\
K. & $\begin{array}{c}\text { Kelompok } \\
\text { Kecil }\end{array}$ & $84,47 \%$ & Sangat layak \\
\multicolumn{4}{c}{ Uji Coba } \\
5elompok \\
Besar
\end{tabular}

Terdapat 19 butir aspek yang dinilai oleh ahli media, 17 butir aspek yang dinilai oleh ahli materi, 17 butir aspek yang dinilai oleh guru, dan 17 butir aspek yang dinilai oleh peserta didik pada uji coba kelompok kecil dan uji coba kelompok besar.

Sebagaimana hasil yang tertera pada Tabel 2, dapat disimpulkan bahwa multimedia tutorial sebagai suplemen pada mata pelajaran Kimia materi Asam dan Basa untuk kelas XI SMA ini sangat layak (valid) digunakan.

Selain data kuantitatif, data kualitatif juga digunakan dalam penelitian ini. Data kualitatif berupa komentar dan saran yang diberikan oleh ahli media, ahli materi, guru, serta peserta didik digunakan sebagai bahan pertimbangan untuk merevisi atau memperbaiki produk.

\section{PEMBAHASAN}

Multimedia tutorial sebagai suplemen pada mata pelajaran Kimia materi Asam dan Basa kelas XI ini mencakup audio visual dalam bentuk teks, gambar, animasi, audio, dan video, sehingga dapat memotivasi dan menarik perhatian peserta didik, serta dapat mendukung tercapainya tujuan pembelajaran. Produk multimedia tutorial ini dibuat menggunakan software AutoPlay Media Studio 8, Adobe Photoshop, dan iSpring Suite 9.
Hasil penelitian yang dilakukan oleh (Admaja, Kuswandi, \& Soepriyanto, 2019; Anas, Soepriyanto, \& ..., 2019; Umroh, Adi, \& Ulfa, 2019; Wardani, Setyosari, \& Husna, 2019) menunjukkan bahwa terdapat pengaruh kemampuan peserta didik dari penggunaan multimedia interaktif model tutorial mengenai materi ajar dimension. Penelitian tersebut menunjukkan hasil bahwa dengan menggunakan multimedia model tutorial, kemampuan peserta didik lebih baik. Pada penelitian yang dilakukan oleh (Lai, 2000; Rosyida \& Adi, 2018; I. Wijaya \& Rakhmawati, 2015; Yusantika, Suyitno, \& Furaidah, 2018) juga menunjukkan hasil yang selaras, yaitu media audio visual berbasis autoplay dapat meningkatkan hasil belajar peserta didik .

Multimedia tutorial sebagai suplemen dapat mengubah materi pembelajaran yang abstrak menjadi konkret. Pada mata pelajaran Kimia materi Asam Basa terdapat beberapa sub bab, dan materi di dalamnya memerlukan ilustrasi dan visualisasi lebih, yang tidak cukup hanya dengan memanfaatkan media cetak (buku, dan sebagainya). Oleh karena itu, diperlukan media pembelajaran tambahan (suplemen) yang dapat membantu tercapainya tujuan pembelajaran.

Suplemen pembelajaran tidak dapat menggantikan peran perangkat pembelajaran utama karena hanya berfungsi sebagai pilihan atau opsional (Hapsari, Toenlioe, \& Soepriyanto, 2019; Jamhari, Susilaningsih, \& Ulfa, 2018; Permatasari, Degeng, \& Adi, 2019). Sifat bahan ajar suplemen opsional, sehingga guru dan peserta didik memiliki kebebasan untuk menggunakannya atau tidak.

Multimedia tutorial sebagai suplemen ini terdiri dari halaman depan, home, profil pengembang, pengantar multimedia tutorial, petunjuk penggunaan multimedia tutorial, kompetensi dasar, materi yang terbagi menjadi empat sub bab (Konsep Asam dan Basa, Indikator Asam dan Basa, Teori Asam dan Basa, serta Kekuatan Asam dan Basa), dan latihan soal. 
Sebagaimana dikemukakan pada penelitian dan pengembangan sebelumnya oleh (Pujiantoro, 2011) yang berjudul "Pengembangan Media Tutorial Berbasis Multimedia Interaktif Pada Mata Pelajaran Teknologi Informasi dan Komunikasi Kelas VIII Semester II di SMP Negeri 1 Mojosari” diperoleh hasil memenuhi kriteria valid atau layak.

Pada penelitian dan pengembangan sebelumnya oleh (Indriana, 2017) yang berjudul "Pengembangan Multimedia Tutorial Mata Pelajaran Ilmu Pengetahuan Alam Pokok Bahasan Sistem Ekskresi Manusia kelas VIII SMP", hasil dari data yang diperoleh melalui validasi ahli media, ahli materi, uji coba perseorangan, uji coba kelompok kecil, dan uji coba lapangan, dapat disimpulkan bahwa multimedia tutorial sistem ekskresi manusia memenuhi kriteria valid.

Berdasarkan penelitian yang dilakukan oleh Wijaya dan Rakhmawati, media pembelajaran Autoplay dalam penelitian tersebut termasuk dalam kategori sangat baik, sehingga layak digunakan sebagai media pembelajaran.

Pada penelitian dan pengembangan multimedia tutorial sebagai suplemen mata pelajaran Kimia materi Asam da Basa Kelas XI SMA dilakukan validasi oleh ahli media, ahli materi, guru, serta uji coba kepada peserta didik. Validasi media dilakukan menggunakan angket (kuesioner) yang terdiri dari 19 butir aspek yang dinilai, serta kolom komentar dan saran. Berdasarkan angket yang diisi oleh ahli media diperoleh hasil 95,78\% dengan kriteria validasi sangat layak. Validasi materi dilakukan menggunakan angket (kuesioner) yang terdiri dari 17 butir aspek yang dinilai, serta kolom komentar dan saran. Berdasarkan angket yang diisi oleh ahli materi diperoleh hasil $83,52 \%$ dengan kriteria validasi sangat layak. Validasi oleh guru dilakukan menggunakan angket (kuesioner) yang terdiri dari 17 aspek yang dinilai, serta kolom komentar dan saran. Berdasarkan angket yang diisi oleh ahli guru diperoleh hasil 85,88\% dengan kriteria validasi sangat layak.

Uji coba kelompok kecil dilakukan kepada 5 peserta didik kelas XI MIPA 5 SMA Negeri 2 Ponorogo. Berdasarkan angket yang diisi oleh 5 peserta didik diperoleh hasil $84,47 \%$ dengan kriteria validasi sangat layak. Uji coba kelompok besar dilakukan kepada 25 peserta didik kelas XI MIPA 5 SMA Negeri 2 Ponorogo. Berdasarkan angket yang diisi oleh 25 peserta didik diperoleh hasil 85,58\% dengan kriteria validasi sangat layak.

Multimedia tutorial sebagai suplemen pada mata pelajaran Kimia materi Asam dan Basa mencakup audio visual dalam bentuk teks, gambar, animasi, audio, dan video, sehingga dapat memotivasi dan menarik perhatian peserta didik, serta dapat mendukung tercapainya tujuan pembelajaran. Oleh karena itu selain dimanfaatkan di SMA Negeri 2 Ponorogo, diharapkan produk ini dapat disebarluaskan ke sekolah-sekolah lain. Diseminasi dapat dilakukan dengan cara sosialisasi produk pengembangan. Dalam proses diseminasi ini, fasilitas serta lingkungan pembelajaran juga harus diperhatikan agar pemanfaatan produk dapat optimal.

Multimedia tutorial ini menyajikan petunjuk penggunaan serta pengantar yang berisi cara penggunaan produk. Sifat bahan ajar suplemen adalah opsional, sehingga guru dan peserta didik memiliki kebebasan untuk menggunakannya atau tidak. Bahan ajar suplemen hanyalah tambahan, tidak dapat menggantikan bahan ajar utama.

Multimedia digunakan dalam pembelajaran bertujuan untuk menarik perhatian dan minat belajar siswa (Umroh et al., 2019). Saat ini pembelajaran menggunakan multimedia dapat dilakukan dengan menggunakan pendekatan digital. Hal itu bertujuan agar siswa terbiasa mengakses laman online untuk kepentingan belajar (Praherdhiono et al., 2019). 
78 JINOTEP (Jurnal Inovasi dan Teknologi Pembelajaran) Kajian dan Riset dalam Teknologi Pembelajaran Vol.6, No. 2, April 2020, Hal 69-80

Terdapat banyak hasil penelitian yang menunjukan hasil belajar yang signifikan melalui penggunaan pembelajaran blended learning (Bralić \& Divjak, 2018; Mouzakis, 2008). Blended learning memberikan banyak kemudahan seperti proses penilaian yang dapat dilakukan dengan cepat. Artinya guru dapat merancang tes online yang dapat diperiksa hasilnya secara cepat dan tepat serta akurat (Mezirow, 1997; Rohmawati, n.d.).

\section{SIMPULAN}

Berdasarkan hasil validasi multimedia tutorial sebagai suplemen oleh ahli media didapatkan persentase sebesar 95,78\%, ahli materi $83,52 \%$, guru $85,88 \%$, serta uji coba kelompok kecil terhadap 5 peserta didik $84,47 \%$, dan uji coba kelompok besar terhadap 20 peserta didik $85,58 \%$. Dapat disimpulkan bahwa multimedia tutorial sebagai suplemen pada mata pelajaran Kimia materi Asam dan Basa kelas XI SMA sangat layak (valid) digunakan. Selain data kuantitatif, data kualitatif juga digunakan dalam penelitian ini. Data kualitatif berupa komentar dan saran yang diberikan oleh responden sebagai bahan pertimbangan untuk merevisi produk.

Saran pemanfaatan multimedia tutorial sebagai suplemen ini dapat digunakan guru pada saat pembelajaran di kelas, maupun sebagai media pembelajaran mandiri bagi peserta didik. Saran pengembangan produk lebih lanjut yaitu, pengembang selanjutnya dapat menambah konten dalam multimedia tutorial (tidak terbatas pada materi Asam dan Basa), mengembangkan produk menjadi lebih fleksibel, sehingga dapat digunakan kapan saja dan dimana saja, serta melakukan uji coba pada skala yang lebih luas.

Pembelajaran dalam jaringan dapat mengintegrasikan berbagai sumber belajar online (Surahman, 2019). Di samping itu pembelajaran online berbasis proyek juga akan memudahkan proses penilaian proyeknya. Penilaian proyek dapat dilakukan secara berkolaborasi antara guru dan siswa melalui model penilaian sebaya (Surahman, Ence;
Soepriyanto, Yerry; Sulthoni; Setyosari, 2019; Surahman, Wedi, Soepriyanto, \& Setyosari, 2018).

Penelitian dan pengembangan ini menghasilkan produk berupa multimedia tutorial sebagai suplemen yang layak pada mata pelajaran Kimia materi Asam dan Basa kelas XI SMA.

\section{DAFTAR RUJUKAN}

Admaja, A., Kuswandi, D., \& Soepriyanto, Y. (2019). Pengembangan Multimedia Tutorial Untuk Guru Dalam Mengembangkan Software Tes Berbasis Komputer. JINOTEP (Jurnal Inovasi Dan Teknologi Pembelajaran) Kajian Dan Riset Dalam Teknologi Pembelajaran, Vol. 5, pp. 63-68. https://doi.org/10.17977/um031v5i22019p06 3

Anas, M. A., Soepriyanto, Y., \& ... (2019) Pengembangan Multimedia Tutorial Topologi Jaringan Untuk Smk Kelas X Teknik Komputer Dan Jaringan. Jurnal Kajian Teknologi .... Retrieved from http://journal2.um.ac.id/index.php/jktp/articl e/view/6916

Arikunto, S. (2000). Manajemen Penelitian edisi baru. Jakarta: Rieneka Cipta. Bandung. Alfabeta. Hlm, 306.

Arikunto, S. (2006). Metodelogi penelitian. Yogyakarta: Bina Aksara.

Arikunto, S. (2009). Dasar-dasar Evaluasi Pendidikan (edisi revisi). Jakarta: Bumi Aksara.

Bralić, A., \& Divjak, B. (2018). Integrating MOOCs in traditionally taught courses: achieving learning outcomes with blended learning. International Journal of Educational Technology in Higher Education, 15(1). https://doi.org/10.1186/s41239-017-0085-7

Hakim, T. (2005). Panduan Menemukan Teknik Belajar, Memilih Jurusan, dan Menentukan Cita-cita; Belajar Secara Efektif. Jakarta: Puspa Swara.

Hapsari, N. D., Toenlioe, A. J. E., \& Soepriyanto, Y. (2019). Pengembangan Augmented Reality Video Sebagai Suplemen Pada Modul Bahasa Isyarat. Jurnal Kajian Teknologi Pendidikan, 1(3), 185-194. 
Hartati, T. (2017). Multimedia in Literacy Development At Remote Elementary Schools in West Java (Multimedia Dalam Pengembangan Literasi Di Sekolah Dasar Terpencil Jawa Barat). Edutech. Retrieved from

http://ejournal.upi.edu/index.php/edutech/art icle/view/4873

Hofstetter, F. T. (2001). Multimedia literacy. McGraw-Hill, Inc.

Indriana, S. (2017). Pengembangan Multimedia Tutorial Mata Pelajaran Ilmu Pengetahuan Alam Pokok Bahasan Sistem Ekskresi Manusia Kelas VIII SMP. SKRIPSI Jurusan Teknologi Pendidikan-Fakultas Ilmu Pendidikan UM.

Jamhari, I., Susilaningsih, S., \& Ulfa, S. (2018). Pengembangan Buku Suplemen 3d Augmented Reality Sebagai Bahan Belajar Tematik Tema Lingkungan Tentang Perkembangbiakan Hewan Untuk Siswa Kelas Iii Sd. JINOTEP (Jurnal Inovasi Dan Teknologi Pembelajaran) Kajian Dan Riset Dalam Teknologi Pembelajaran, Vol. 4, pp. 76-81. https://oi.org/10.17977/um031v4i22018p07 6

Kemendikbud. (2013). Peraturan Menteri Pendidikan Nasional No. 87 tahun 2013 tentang Program Pendidikan Profesi Guru Prajabatan Pasal 1. Kelembagaan Ristekdikti. Retrieved from https://kelembagaan.ristekdikti.go.id/wpcontent/uploads/2016/11/permen_tahun2013 _nomor87.pdf

Khoerunisa, M., Maknun, D., \& Mulyani, A. (2014). Pembelajaran Bioteknologi berbasis Multimedia Tutorial untuk meningkatkan hasil Belajar Siswa kelas IX di SMPN 8 Kota Cirebon. Scientiae Educatia: Jurnal Pendidikan Sains, 3(2), 55-70.

Lai, S.-L. (2000). Influence of audio-visual presentations on learning abstract concepts. International Journal of Instructional Media, 27(2), 199.

Lee, W. W., \& Owens, D. L. (2004). Multimediabased instructional design: computer-based training, web-based training, distance broadcast training, performance-based solutions. John Wiley \& Sons.

Mayer, R. E., \& Moreno, R. (1998). A cognitive theory of multimedia learning: Implications for design principles. Journal of Educational Psychology, 91(2), 358-368.
Mayer, R., \& Mayer, R. E. (2005). The Cambridge handbook of multimedia learning. Cambridge university press.

Mezirow, J. (1997). Transformative learning: Theory to practice. New Directions for Adult and Continuing Education, 1997(74), 5-12.

Mohsen, M. A. (2016). The use of help options in multimedia listening environments to aid language learning: a review. British Journal of Educational Technology, 47(6), 1232 1242.

Moreno, R., \& Mayer, R. E. (2000). A learnercentered approach to multimedia explanations: Deriving instructional design principles from cognitive theory. Interactive Multimedia Electronic Journal of ComputerEnhanced Learning, 2(2), 12-20.

Mouzakis, C. (2008). Teachers' perceptions of the effectiveness of a blended learning approach for ICT teacher training. Journal of Technology and Teacher Education, 16(4), 461-482.

Permatasari, K., Degeng, I. N. S., \& Adi, E. P. (2019). Pengembangan Suplemen Video Pembelajaran Adaptasi Makhluk Hidup untuk Siswa Tunarungu SLB-B YPLB Blitar. Jurnal Kajian Teknologi .... Retrieved from http://journal2.um.ac.id/index.php/jktp/articl e/view/268

Praherdhiono, H., Setyosari, P., Degeng, I. N. S., Slamet, T. I., Surahman, E., Adi, E. P., ... Abidin, Z. (2019). Teori dan Implementasi Teknologi Pendidikan: Era Belajar Abad 21 dan Revolusi Industri 4.0. Seribu Bintang.

Pujiantoro, W. (2011). Pengembangan media tutorial berbasis multimedia interaktif mata pelajaran teknologi informasi dan komunikasi kelas VIII semester II di smp negeri 1 Mojosari. SKRIPSI Jurusan Teknologi Pendidikan-Fakultas Ilmu Pendidikan UM.

Rohmawati, T. (n.d.). THE Effectiveness Of Teaching Performance Assessment (PKG) Program Online Report Via Website at Tangerang City Education .... EDUTECH. Retrieved from https://ejournal.upi.edu/index.php/edutech/ar ticle/view/4871

Rosyida, F., \& Adi, K. R. (2018). Pelatihan Pembuatan Media Pembelajaran dengan Program Autoplay untuk Guru-Guru SMPN 2 Balen Kecamatan Balen Kabupaten 
80 JINOTEP (Jurnal Inovasi dan Teknologi Pembelajaran) Kajian dan Riset dalam Teknologi Pembelajaran Vol.6, No. 2, April 2020, Hal 69-80

Bojonegoro. Jurnal Praksis Dan Dedikasi Sosial, 1(1), 21-29.

Schunk, D. H. (2012). Learning theories an educational perspective sixth edition. Pearson.

Setyosari, P. (2017). Menciptakan Pembelajaran yang Efektif dan Berkualitas. JINOTEP (Jurnal Inovasi Dan Teknologi Pembelajaran) Kajian Dan Riset Dalam Teknologi Pembelajaran, pp. 20-30. https://doi.org/10.17977/um031v1i12014p02 0

Sunarya, P. A., Rahardja, U., Aini, Q., \& Khoirunisa, A. (n.d.). Implementasi Gamifikasi Sebagai Manajemen Pendidikan Untuk Motivasi Pembelajaran. EDUTECH. Retrieved from https:/ejournal.upi.edu/index.php/edutech/ar ticle/view/14697

Surahman, Ence; Soepriyanto, Yerry; Sulthoni; Setyosari, P. (2019). Model Peer Collaborative Authentic Assessment (PECOLASE). Indonesia: 000139977.

Surahman, E. (2019). Integrated Mobile Learning System (IMOLES) sebagai Upaya Mewujudkan Masyarakat Pebelajar Unggul Era Digital. JINOTEP (Jurnal Inovasi Dan Teknologi Pembelajaran) Kajian Dan Riset Dalam Teknologi Pembelajaran, 5(2), 5056.

Surahman, E., Wedi, A., Soepriyanto, Y., \& Setyosari, P. (2018). Design of Peer Collaborative Authentic Assessment Model Based on Group Project Based Learning to Train Higher Order Thinking Skills of Students. International Conference on Education and Technology (ICET 2018). Atlantis Press.

Tuerah, R. M. S. (2017). Penguasaan Materi Pembelajaran, Manajemen Dan Komitmen
Menjalankan Tugas Berkorelasi Pada

Kinerja Guru Sd Di Kota Tomohon. ... Jurnal Inovasi Dan Teknologi Pembelajaran) Kajian .... Retrieved from http://journal2.um.ac.id/index.php/jinotep/ar ticle/view/2120

Umroh, N. S., Adi, E. P., \& Ulfa, S. (2019). Multimedia Tutorial Untuk Menumbuhkan Minat Baca Anak Adhd (Attention Deficit Hyperactivity Disorder). Jurnal Kajian Teknologi Pendidikan. Retrieved from http://journal2.um.ac.id/index.php/jktp/articl e/view/7628

Wardani, S. K., Setyosari, P., \& Husna, A. (2019). PENGEMBANGAN Multimedia Tutorial Mata Pelajaran Ipa Pokok Bahasan Sistem Tata Surya Kelas Vii Mts Raudlatul Ulum .... Jurnal Kajian Teknologi .... Retrieved from

http://journal2.um.ac.id/index.php/jktp/articl e/view/7370

Wijaya, A. R., Kuswandi, D., \& ... (2019). Pengembangan Multimedia Interaktif Dengan Topik Kolonialisme Dan Imperialisme Di Indonesia Pada Mata Pelajaran IPS Kelas VIII. JINOTEP (Jurnal Inovasi .... Retrieved from http://journal2.um.ac.id/index.php/jinotep/ar ticle/view/6904

Wijaya, I., \& Rakhmawati, L. (2015). Pengembangan Media Pembelajaran Autoplay Media Studio pada Mata Pelajaran Perekayasaan Sistem Audio di SMK Negeri 3 Surabaya. Jurnal Pendidikan Teknik Elektro, 4(3).

Yusantika, F. D., Suyitno, I., \& Furaidah, F. (2018). Pengaruh Media Audio dan Audio Visual terhadap Kemampuan Menyimak Siswa Kelas IV. Jurnal Pendidikan: Teori, Penelitian, Dan Pengembangan, 3(2), 251258. 